\title{
Clinical significance of hepatitis B virus-DNA in hepatocellular carcinoma negative for hepatitis $B$ virus surface antigen
}

\author{
SHINPEI TATEIWA ${ }^{1}$, YOSHIHIKO YANO ${ }^{2}$, YASUSHI SEO ${ }^{2}$, AKIRA MIKI ${ }^{2}$, \\ KAWANO YUUKI $^{2}$, TAKESHI AZUMA ${ }^{2}$ and YOSHITAKE HAYASHI ${ }^{1}$ \\ ${ }^{1}$ Center for Infectious Disease, ${ }^{2}$ Division of Gastroenterology, \\ Kobe University Graduate School of Medicine, Kobe 650-0017, Japan
}

Received November 11, 2009; Accepted December 22, 2009

DOI: 10.3892/etm_00000053

\begin{abstract}
It is relatively rare for hepatocellular carcinoma (HCC) to develop in patients that are serologically negative for hepatitis B virus surface antigen (HBsAg) or antihepatitis $\mathrm{C}$ virus antibody (HCV-Ab). In addition, hepatitis B virus (HBV) is sometimes detected and associated with hepatocarcinogenesis in $\mathrm{HCC}$ cases without HBsAg and HCV-Ab (NBNC-HCC). In this study we focused on the characteristics of resected NBNC-HCC, and occult HBV infection in resected liver tissues was also examined in these cases. A total of 32 cases ( 26 males and 6 females, median age $65.7 \pm 13.9$ years) that underwent liver resection were enrolled in this study. Clinical data from 19 cases with NBNC-HCC were compared with those from 13 cases of HCC related to hepatitis viruses (HV-HCC). Subsequently, occult HBV infection was assessed by the detection of HBV-DNA from extracted liver tissue in NBNC-HCC. Mutation and variation were also examined by the PCR-direct sequencing method in the occult HBV cases. The average diameter of NBNC-HCC was significantly larger than that of HV-HCC. In addition, the activity and fibrosis scores of the surrounding liver tissues were significantly higher in HV-HCC. Among 19 cases of NBNC-HCC, HBV-DNA was detected in 7. Four out of the 7 cases were detected in the Pre-S/S region. The insertion of four amino acids in the $\alpha$-loop region was detected in 1 case. No significant difference between the occult HBV cases and the others was found in NBNC-HCC. All cases were classified into genotype $\mathrm{C}$ on phylogenetic analysis. HBV-DNA was frequently detected in the liver tissues of NBNC-HCC. Thus, our data revealed that HBV may be associated with hepatocarcinogenesis in cases of occult HBV infection.
\end{abstract}

Correspondence to: Dr Yoshihiko Yano, Center for Infectious Disease, Kobe University Graduate School of Medicine, 6-5-1 Chuo-ku, Kusunoki-cho, Kobe 650-0017, Japan

E-mail: yanoyo@med.kobe-u.ac.jp

Key words: hepatocellular carcinoma, occult hepatitis B virus, hepatocarcinogenesis

\section{Introduction}

Hepatocellular carcinoma (HCC) can be a fatal, and chronic infection caused by hepatitis B virus (HBV) and/or hepatitis $\mathrm{C}$ virus (HCV) is usually related to hepatocarcinogenesis. Globally, HBV carriers are estimated to total 3 million, and approximately 1 million people suffer from HBV-related HCC (1). HBV is an oncogenic virus which integrates with the genome of hepatocytes. The quantity of HBV-DNA is strongly associated with the generation of $\operatorname{HCC}(2,3)$.

In general, the diagnosis of HBV infection is based on the detection of hepatitis B surface antigen (HBsAg) in the serum. However, it was recently reported that HBV-DNA is periodically detected in the serum or liver and is recognized as occult $\mathrm{HBV}$ infection $(4,5)$. In particular, $\mathrm{HBcAb}$ positivity is thought to be a latent risk factor for hepatocarcinogenesis, since the covalently closed circular DNA (cccDNA) of HBV is responsible for the persistent HBV infection of hepatocytes in these cases $(6,7)$.

In order to examine the clinical characteristics of $\mathrm{HCC}$ negative for $\mathrm{HBsAg}$ and the anti-hepatitis $\mathrm{C}$ virus antibody (HCV-Ab) (NBNC-HCC) and HBV-DNA in relation to hepatocarcinogenesis in NBNC-HCC, 32 cases of resected HCC were analyzed.

\section{Materials and methods}

Sample collection. Thirty-two cases of HCC (26 males and 6 females, median age 65.7 years) that underwent surgical resection in Kobe University and related hospitals were enrolled in this study. Clinical characteristics including age, gender, biochemical data and surrounding liver tissues were examined. Histological features were graded according to the New Inuyama Classification (8).

Analysis of occult HBV infection. To examine occult HBV infection in HBsAg-negative cases, DNA was extracted in 12 cases from surrounding liver tissues using the QIAamp DNA Mini Kit (Qiagen, Tokyo, Japan). The detection of HBV-DNA was carried out by employing PCR analysis using specific primers $(9,10)$. PCR products were directly sequenced using an ABI PRISM ${ }^{\circledR} 3100$ Avant Genetic Analyzer (Applied Biosystems, Foster City, CA, USA), and nucleotide align- 
Table I. Clinical characteristics of NBNC-HCC and hepatitis virus-related HCC.

\begin{tabular}{lccc}
\hline & NBNC-HCC & HV-HCC & P-value \\
\hline Cases (no.) & 19 & 13 & 0.0794 \\
Age (years) & $68.70 \pm 8.27$ & $4.40 \pm 14.50$ & $0.0415^{\text {a }}$ \\
Tumor size (mm) & $74.70 \pm 36.20$ & $1.090 \pm 0.302$ & $0.0019^{\text {a }}$ \\
Activity & $0.50 \pm 0.514$ & $3.000 \pm 0.444$ & $0.0061^{\text {a }}$ \\
Fibrosis & $1.53 \pm 1.81$ & $15.90 \pm 8.01$ & 0.1849 \\
PLT (x10 $/ \mu \mathrm{l})$ & $20.40 \pm 9.80$ & $46.50 \pm 26.50$ & 0.6151 \\
ALT (IU/l) & $41.40 \pm 28.20$ & $13,508 \pm 24,412$ & 0.0984 \\
AFP (ng/ml) & $1,302 \pm 3,988$ & $923 \pm 1,250$ & 0.0738 \\
PIVKA-II (mAU/ml) & $16,672 \pm 36,142$ & & \\
\hline
\end{tabular}

NBNC-HCC, HCC without HBsAg and HCV-Ab; HV-HCC, hepatitis virus-related HCC; PLT, platelets; ALT, alanine transaminases; AFP, $\alpha$-fetoproteins; PIVKA-II, prothrombin induced by vitamin K absence or antagonist-II. Data are the mean \pm SD. ${ }^{a} \mathrm{p}<0.05$.

Table II. Clinical data of NBNC-HCC between occult HBV-infected cases and others.

\begin{tabular}{lccc}
\hline & Occult HBV in NBNC-HCC & Non-occult HBV in NBNC-HCC & P-value \\
\hline Cases (no.) & 7 & $70.10 \pm 6.45$ & 0.2925 \\
Age (years) & $65.7 \pm 11.4$ & $70.2 \pm 10.2$ & 0.4335 \\
Tumor size (mm) & $84.7 \pm 46.3$ & $0.615 \pm 0.137$ & 0.1284 \\
Activity & $0.20 \pm 0.22$ & $1.540 \pm 0.457$ & 0.6530 \\
Fibrosis & $1.170 \pm 0.672$ & $18.50 \pm 2.68$ & 0.2341 \\
PLT $\left(x 10^{4} / \mu \mathrm{l}\right)$ & $24.40 \pm 3.91$ & $42.8 \pm 27.2$ & 0.7690 \\
ALT $(\mathrm{IU} / \mathrm{l})$ & $38.5 \pm 33.0$ & $17.80 \pm 2.01$ & 0.0199 a \\
ICG-R 15\% $(\%)$ & $11.30 \pm 1.62$ & & \\
\hline
\end{tabular}

PLT, platelets; ALT, alanine transaminases; ICG, indocyanine green test. Data are the mean \pm SD. ${ }^{\mathrm{a}} \mathrm{p}<0.05$.

ment using 20 reference strains was performed with Clustal $\mathrm{X}$ software. The HBV genotype was determined by phylogenetic analysis using the Molecular Evolutionary Genetics Analysis 4 (MEGA4) software program (available at http:// www.megasoftware.net) (11).

Statistical analysis. Statistical analysis was carried out using JMP7 software (SAS Institute Japan, Co., Ltd.). P<0.05 was considered significant.

\section{Results}

Clinical data. The etiology of the HCC cases is illustrated in Fig. 1. Seven cases (22\%) were positive for HBsAg, 6 (19\%) were positive for $\mathrm{HCV}-\mathrm{Ab}$ and $19(59 \%)$ were negative for both HBsAg and HCV-Ab. Clinical data in the hepatitis virusrelated $\mathrm{HCC}$ (HV-HCC) cases were compared with those in NBNC-HCC (Table I). The activity and fibrosis scores of the background liver tissues in $\mathrm{HV}-\mathrm{HCC}$ were higher than those in NBNC-HCC. The average diameter of the cancer in HV-HCC was smaller than that in NBNC-HCC.

Occult $H B V$ infection in NBNC-HCC. To examine occult HBV infection, HBV-DNA was assessed by PCR analysis from

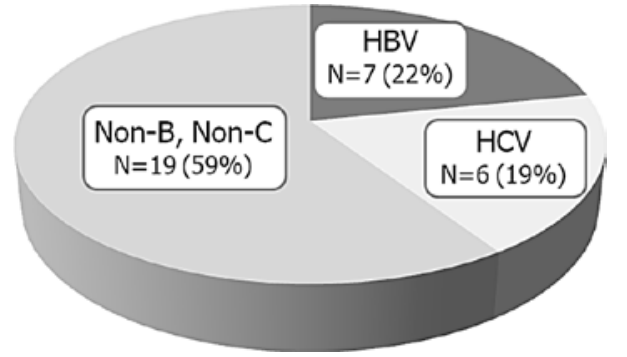

Figure 1. Serological background of surgically operated HCC. Seven cases (22\%) were positive for HBsAg, 6 (19\%) were positive for HCV-Ab and 19 (59\%) were negative for both HBsAg and HCV-Ab.

extracted liver tissue in NBNC-HCC. The total characteristics of occult HBV were clinically compared with those of non-occult HBV cases (Table II). No significant difference, excluding the indocyanine green test, was detected between the two groups.

HBV-DNA in the pre-S/S region was amplified and detected in 4 out of 7 cases $(57 \%)$; the $X$ region was detected in 4 cases $(57 \%)$, and the core promoter/pre-core region was detected in 3 cases (43\%). Mutation of codon 38 was detected in 1 case $(12,13) . \mathrm{C} 1653 \mathrm{~T}$ in the enhancer box $\alpha$-region was 
Table III. Mutation/variation of occult HBV infection.

\begin{tabular}{|c|c|c|c|c|c|}
\hline \multirow[t]{2}{*}{ Case no. } & \multirow[t]{2}{*}{ HBsAg } & \multirow[t]{2}{*}{ Pre-S/S } & \multicolumn{2}{|c|}{$\mathrm{X}$ region } & \multirow{2}{*}{$\frac{\text { BCP region }}{\mathrm{A} 1762 \mathrm{~T} / \mathrm{G} 1764 \mathrm{~A}}$} \\
\hline & & & $\mathrm{C} 1653 \mathrm{~T}$ & $\mathrm{~T} 1753 \mathrm{~V}$ & \\
\hline 2 & ND & ND & $\mathrm{T}$ & $\mathrm{T}$ & $\mathrm{T} / \mathrm{A}$ \\
\hline 3 & ND & ND & $\mathrm{T}$ & $\mathrm{T}$ & $\mathrm{T} / \mathrm{A}$ \\
\hline 5 & + & + & $\mathrm{T}$ & $\mathrm{T}$ & T/A \\
\hline 6 & + & 4-AA insertion & ND & ND & ND \\
\hline 11 & - & + & ND & ND & ND \\
\hline 12 & ND & + & ND & ND & ND \\
\hline 16 & + & ND & $\mathrm{C}$ & $\mathrm{T}$ & ND \\
\hline
\end{tabular}

BCP, basic core promoter; ND, not determined; AA, amino acid.

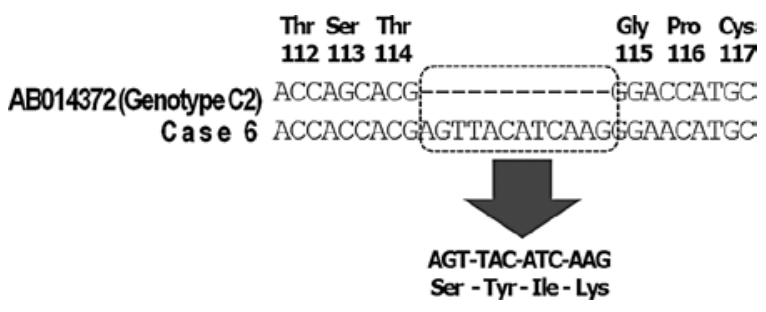

Figure 2. Alignment of the $\mathrm{S}$ genome in NBNC-HCC. A 12-nucleotide insertion (4-amino acid insertion) was detected in case no. 6. The nucleotide sequence was aligned and compared with the reference genotype $\mathrm{C}$ strain from Japan.

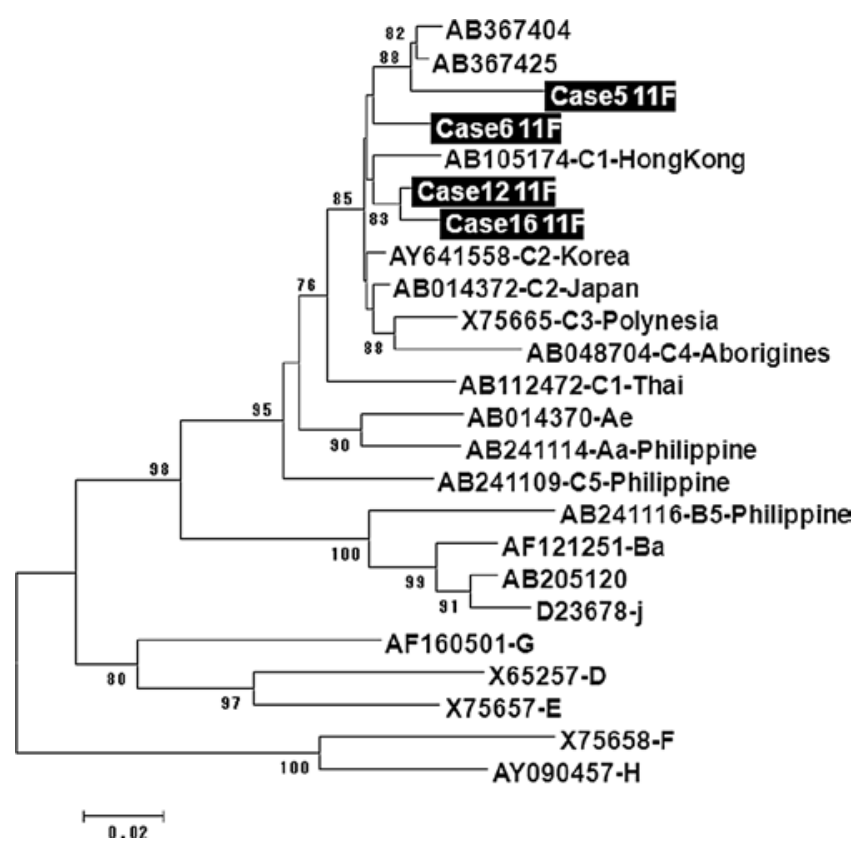

Figure 3. Phylogenetic analysis of HBV-DNA in NBNC-HCC. The HBV genotype was determined by phylogenetic analysis based on the Pre-S/S region. The nucleotide sequence was amplified and compared with 20 reference sequences. All 4 cases were grouped into genotype C.

found in 3 out of 4 cases, and A1762T/G1764A in the basic core promoter region was detected in all 4 cases (Table III). A 12-nucleotide insertion (4-amino acid insertion) in the $\mathrm{S}$ region was noted in 1 case (Fig. 2). Phylogenetic analysis showed that all 4 cases were grouped into genotype C (Fig. 3).

$\mathrm{HBcAb}$ was serologically examined in 12 out of 19 NBNC-HCC cases. Five out of 12 cases (42\%) were positive for $\mathrm{HBcAb}$, which were thought to have been previously infected and resolved naturally.

\section{Discussion}

Liver resection for $\mathrm{HCC}$ is a potentially curative treatment. However, it has been reported that resection is possible in only $30-35 \%$ of the HCC cases evaluated for surgical therapy due to co-existing cirrhosis or the multicentric generation of HCC (14). NBNC-HCC is estimated to comprise $10 \%$ of HCC in Japanese patients. In this study, 19 out of 32 resected HCC cases $(56 \%)$ were diagnosed as NBNC-HCC. It has been suggested that cases of hepatic fibrosis of HCC with hepatitis viral infection are usually more severe than those of NBNC-HCC. In this study, HCC of more than $5 \mathrm{~cm}$ in diameter was present in 13 out of 19 cases $(68 \%)$ of NBNC-HCC. In addition, the average diameter of NBNC-HCC was larger than that of HV-HCC. It is thought that HV-HCC is diagnosed at an early stage, since patients with chronic infection of hepatitis virus are regularly examined. It was recently reported that the prevalence of non-alcoholic steatohepatitis is increasing among NBNC-HCC cases (15). In this study, 5 cases (26\%) showed impaired glucose tolerance, and 3 cases (16\%) were obese. Thus our findings indicated that abnormal glucose tolerance was associated with hepatocarcinogenesis in this study.

Occult $\mathrm{HBV}$ infection is diagnosed when $\mathrm{HBsAg}$ in serum is negative and HBV-DNA in serum or liver is positive, regardless of the positivity for anti-HBc. It is still controversial whether or not occult HBV infection is associated with liver damage. Althought it was reported that occult HBV infection does not progress to severe liver disease (16), another study showed that occult HBV infection caused liver disease progression in cases of chronic infection of $\mathrm{HCV}(17,18)$. In this study, the activity and fibrosis scores in the HCC cases with occult HBV infection were lower than those in HV-HCC. Thus, our data indicated that occult HBV infection is not related to the progression of liver disease. As for hepatocarcinogenesis, it is also controversial whether or not occult HBV infection 
is associated with HCC. Although it was reported that occult $\mathrm{HBV}$ infection is an independent risk factor for carcinogenesis in patients with $\operatorname{HCV}(19,20)$, another study showed that occult HBV infection was not related to hepatocarcinogenesis (21).

Several studies have demonstrated that the basic core promoter region in the HBV genome is associated with hepatocarcinogenesis $(22,23)$. In Japan, it was reported that C1653T and T1753V are associated with HCC $(24,25)$. Although T1753V was detected in only 1 case, C1653T and A1762T/G1764A were relatively common in this study. It was also reported that a mutation of the $X$ region is associated with $\operatorname{HCC}(12,13)$, but the codon 38 mutation was detected in only 1 case and no mutation was found in codon 31 in the present study. It is probable that the mutation/variation in occult $\mathrm{HBV}$ infection in relation to $\mathrm{HCC}$ is different from that in $\mathrm{HBsAg}$-positive cases. A recent study showed that virological factors of $\mathrm{HBV}$ related to $\mathrm{HCC}$ are different between occult $\mathrm{HBV}$-infected and $\mathrm{HBsAg-positive}$ patients, and G1721A, M1I and Q2K in the pre-S2 gene might be useful viral markers for HCC in occult HBV carriers (24).

In this study, a 12-nucleotide insertion (4-amino acid insertion) between nt 114 and 115 in the $S$ region was found in 1 case (Fig. 2). We considered that the $\alpha$-loop region in the $S$ region was important for the conformation of the $S$ antigen, and amino acid substitutions at 122, 123, 126, 141 and 145 were found in the vaccine-escaping mutant. It was possible that the insertion caused the conformational change to the $\mathrm{S}$ antigen, and this resulted in the serological HBsAg negativity in this case. It has also been reported that several insertions in the HBx and Pre-S2 regions are associated with $\operatorname{HCC}(25,26)$, but there were no such mutations identified in this study.

In the present study, phylogenetic analysis revealed that all cases of occult HBV infection were grouped into genotype C. Since HBV genotype $\mathrm{C}$ is the most prevalent in Japanese patients, it is reasonable that occult HBV in Japan is derived from genotype $\mathrm{C}$.

In conclusion, HBV-DNA was frequently found in the NBNC-HCC tissues. No significant difference was noted between occult $\mathrm{HBV}$ and other forms of infection among the NBNC-HCC cases. Therefore, further investigation is necessary to assess whether occult HBV infection is related to hepatocarcinogenesis.

\section{Acknowledgements}

This study was supported by a grant-in-aid through the Program of Founding Research Centers for Emerging and Reemerging Infectious Diseases, the Ministry of Education, Culture, Sports, Science and Technology (MEXT), Japan.

\section{References}

1. Lee WM: Hepatitis B virus infection. N Engl J Med 337 1733-1743, 1997.

2. Tang B, Kruger WD, Chen G, et al: Hepatitis B viremia is associated with increased risk of hepatocellular carcinoma in chronic carriers. J Med Virol 72: 35-40, 2004.

3. Harris RA, Chen G, Lin WY, Shen FM, London WT and Evans AA: Spontaneous clearance of high-titer serum HBV DNA and risk of hepatocellular carcinoma in a Chinese population. Cancer Causes Control 14: 995-1000, 2003.

4. Shih LN, Sheu JC, Wang JT, et al: Serum hepatitis B virus DNA in healthy HBsAg-negative Chinese adults evaluated by polymerase chain reaction. J Med Virol 32: 257-260, 1990.
5. Marusawa H, Uemoto S, Hijikata M, et al: Latent hepatitis B virus infection in healthy individuals with antibodies to hepatitis B core antigen. Hepatology 31: 488-495, 2000.

6. Tuttleman JS, Pourcel C and Summers J: Formation of the pool of covalently closed circular viral DNA in hepadnavirus-infected cells. Cell 47: 451-460, 1986.

7. Seeger C and Mason WS: Hepatitis B virus biology. Microbiol Mol Biol Rev 64: 51-68, 2000.

8. Ichida F, Tsuji T, Omata M, et al: New Inuyama Classification; new criteria for histological assessment of chronic hepatitis. Int Hepatol Commun 6: 112-119, 1996.

9. Sugauchi F, Mizokami M, Orito E, et al: A novel variant genotype $\mathrm{C}$ of hepatitis $\mathrm{B}$ virus identified in isolates from Australian Aborigines: complete genome sequence and phylogenetic relatedness. J Gen Virol 82: 883-892, 2001.

10. Sugauchi F, Ohno T, Orito E, et al: Influence of hepatitis B virus genotypes on the development of preS deletions and advanced liver disease. J Med Virol 70: 537-544, 2003.

11. Tamura K, Dudley J, Nei M and Kumar S: MEGA4: Molecular Evolutionary Genetics Analysis (MEGA) software version 4.0. Mol Biol Evol 24: 1596-1599, 2007.

12. Yeh CT, Shen CH, Tai DI, Chu CM and Liaw YF: Identification and characterization of a prevalent hepatitis $\mathrm{B}$ virus $\mathrm{X}$ protein mutant in Taiwanese patients with hepatocellular carcinoma. Oncogene 19: 5213-5220, 2000.

13. Muroyama R, Kato N, Yoshida H, et al: Nucleotide change of codon 38 in the $\mathrm{X}$ gene of hepatitis $\mathrm{B}$ virus genotype $\mathrm{C}$ is associated with an increased risk of hepatocellular carcinoma. J Hepatol 45: 805-812, 2006.

14. Sotiropoulos GC, Lang H, Frilling A, et al: Resectability of hepatocellular carcinoma: evaluation of 333 consecutive cases at a single hepatobiliary specialty center and systematic review of the literature. Hepatogastroenterology 53: 322-329, 2006.

15. Hatanaka K, Kudo M, Fukunaga T, et al: Clinical characteristics of NonBNonC-HCC: comparison with HBV and HCV-related HCC. Intervirology 50: 24-31, 2007.

16. Kao JH, Chen PJ, Lai MY and Chen DS: Occult hepatitis B virus infection and clinical outcomes of patients with chronic hepatitis C. J Clin Microbiol 40: 4068-4071, 2002.

17. Mrani S, Chemin I, Menouar K, et al: Occult HBV infection may represent a major risk factor of non-response to antiviral therapy of chronic hepatitis C. J Med Virol 79: 1075-1081, 2007.

18. Tamori A, Nishiguchi S, Kubo S, et al: Possible contribution to hepatocarcinogenesis of X transcript of hepatitis B virus in Japanese patients with hepatitis C virus. Hepatology 29: 1429-1434, 1999.

19. Pollicino T, Squadrito G, Cerenzia G, et al: Hepatitis B virus maintains its pro-oncogenic properties in the case of occult $\mathrm{HBV}$ infection. Gastroenterology 126: 102-110, 2004.

20. Tamori A, Hayashi T, Shinzaki M, et al: Frequent detection of hepatitis B virus DNA in hepatocellular carcinoma of patients with sustained virologic response for hepatitis $\mathrm{C}$ virus. J Med Virol 81: 1009-1014, 2009.

21. Kusakabe A, Tanaka Y, Orito E, et al: A weak association between occult HBV infection and non-B non-C hepatocellular carcinoma in Japan. J Gastroenterol 42: 298-305, 2007.

22. Kim JK, Chang HY, Lee JM, et al: Specific mutations in the enhancer II/core promoter/precore regions of hepatitis B virus subgenotype $\mathrm{C} 2$ in Korean patients with hepatocellular carcinoma. J Med Virol 81: 1002-1008, 2009.

23. Kao JH, Chen PJ, Lai MY and Chen DS: Basal core promoter mutations of hepatitis B virus increase the risk of hepatocellular carcinoma in hepatitis B carriers. Gastroenterology 124: 327-334, 2003.

24. Shinkai N, Tanaka Y, Ito K, et al: Influence of hepatitis B virus X and core promoter mutations on hepatocellular carcinoma among patients infected with subgenotype C2. J Clin Microbiol 45: 3191-3197, 2007.

25. Tanaka Y, Mukaide M, Orito E, et al: Specific mutations in enhancer II/core promoter of hepatitis B virus subgenotypes $\mathrm{C} 1$ / $\mathrm{C} 2$ increase the risk of hepatocellular carcinoma. J Hepatol 45: 646-653, 2006.

26. Chen $\mathrm{CH}$, Changchien CS, Lee CM, et al: A study on sequence variations in pre-S/surface, $\mathrm{X}$ and enhancer II/core promoter/ precore regions of occult hepatitis $\mathrm{B}$ virus in non- $\mathrm{B}$, non-C hepatocellular carcinoma patients in Taiwan. Int J Cancer 125: 621-629, 2009.

27. Tabor E: Pathogenesis of hepatitis B virus-associated hepatocellular carcinoma. Hepatol Res 37: 110-114, 2007.

28. Lupberger J and Hildt E: Hepatitis B virus-induced oncogenesis. World J Gastroenterol 13: 74-81, 2007. 